\title{
STRUKTUR KOMUNITAS MAKROALGA DI PANTAI GEGER DAN PANTAI MENGENING KABUPATEN BADUNG
}

\section{THE MACROALGAE COMMUNITY STRUCTURE IN GEGER BEACH AND MENGENING BEACH BADUNG REGENCY}

\author{
Ni Putu Sintha Maharani ${ }^{1}$, Ni Luh Watiniasih ${ }^{2}$, Ayu Putu Wiweka Krisna Dewi ${ }^{3}$ \\ 1. Program Studi Manajemen Sumberdaya Perairan, Fakultas Kelautan dan Perikanan, Universitas Udayana, \\ Bukit Jimbaran, Kabupaten Badung, Bali-Indonesia. \\ 2. Fakultas Matematika dan Ilmu Pengetahuan Alam, Universitas Udayana, Bukit Jimbaran, Kabupaten \\ Badung, Bali-Indonesia \\ Email : luhwatiniasih@unud.ac.id
}

\begin{abstract}
ABSTRAK
Makroalga dikenal sebagai rumput laut dan tergolong ke dalam tumbuhan tingkat rendah dimana organ-organ yang berupa akar, batang, dan daun relatif sulit untuk dibedakan. Penelitian ini bertujuan untuk mengetahui perbedaan karakteristik habitat, jumlah jenis, biomassa serta struktur komunitas makroalga di Pantai Geger dan Pantai Mengening. Penelitian ini menggunakan metode survei dengan cara pengambilan data dengan menggunakan metode transek kuadran. Hasil penelitian menunjukkan bahwa Pantai Geger memiliki karakteristik substrat berpasir sedangkan Pantai Mengening memiliki substrat yang terdiri dari batuan karang. Kondisi kualitas perairan di kedua lokasi masih sesuai untuk pertumbuhan makroalga. Dari hasil penelitian ditemukan 8 jenis makroalga di Pantai Geger dan 10 jenis makroalga di Pantai Mengening. Nilai biomassa makroalga tertinggi di Pantai Geger terdapat pada jenis Gracilaria hayi dengan bobot berkisar antara 72,08-73,18 g/m² sedangkan nilai biomassa makroalga tertinggi di Pantai Mengening terdapat pada jenis Valonia aegagropila yang berkisar antara 181,31-190,40 g/ $\mathrm{m}^{2}$. Berdasarkan hasil nilai indeks keanekaragaman makroalga di Pantai Geger sebesar 1,93-1,99 sedangkan di Pantai Mengening sebesar 1,79-2,07 sehingga termasuk kedalam ketegori sedang. Nilai indeks dominansi makroalga di Pantai Geger sebesar 0,15-0,17 sedangkan di Pantai Mengening sebesar 0,17-0,25, sehingga nilai indeks dominansi di kedua pantai tersebut termasuk dalam kategori rendah. Nilai indeks kemerataan di Pantai Geger sebesar 0,93-0,96 sedangkan di Pantai Mengening sebesar 0,78-0,90, sehingga nilai indeks kemerataan di kedua pantai tersebut termasuk kedalam kategori kondisi stabil.
\end{abstract}

Kata Kunci: struktur komunitas, makroalga, Pantai Geger, Pantai Mengening.

\section{ABSTRACT}

Macroalgae is a type of flora known as seaweed and is classified into low-level plants, where roots, stems, and leaves are relatively difficult to distinguish. This study aims to determine the differences of habitat characteristics, number of species, biomass, and macroalgae community structure in Geger Beach and Mengening Beach. This quadrant transect method was used to collect the data. The results show that Geger Beach has sandy substrate, while Mengening Beach has substrate consisting of coral rock. The water quality in both locations are still suitable for macroalgae growth. The results of the study found 8 types of macroalgae in Geger Beach and 10 types of macroalgae in Mengening Beach. The highest macroalgae biomass at Geger Beach was found in Gracilaria hayi with the weight ranging from 72.08-73.18 g/ $\mathrm{m}^{2}$, while at Mengening Beach was found in the Valonia aegagropila, ranging from $181.31-190.40 \mathrm{~g} / \mathrm{m}^{2}$. The diversity index of macroalgae in Geger Beach was between 1.93-1.99, while at Mengening Beach was between 1.79-2.07, therefore categorized as medium. The dominance index of macroalgae at Geger Beach was between 0.15-0.17, 
while at Mengening Beach was between 0.17-0.25, therefore the dominance index at both site was categorized low. The evenness index at Geger Beach was between 0.93-0.96, while at Mengening Beach was between 0.78-0.90, which categorized as stable conditions.

\section{Keywords: communitysStructure, macroalgae, Geger Beach, Mengening Beach}

\section{PENDAHULUAN}

Perairan laut Indonesia kaya akan berbagai biota laut baik flora maupun fauna potensial dan memiliki peranan penting secara ekologi dan ekonomi. Makroalga termasuk salah satu dari bagian flora yang dikenal sebagai rumput laut dan torgolong ke dalam tumbuhan tingkat rendah dimana organ-organ yang berupa akar, batang, dan daun relatif sulit untuk dibedakan. Makroalga terbagi menjadi 3 devisi berdasarkan kandungan pigmen yang dominan diantaranya: Rhodophyta (alga merah), Phaeophyta (alga coklat) dan Chlorophyta (alga hijau). Makroalga ditemukan tumbuh pada 2 tipe substrat yaitu substrat lunak yang terdiri dari campuran pasir dan lumpur serta substrat keras yang terdiri dari karang mati, karang hidup dan batuan. Makroalga yang hidup di daerah tropis memiliki keanekaragaman spesies yang sangat tinggi, namun sangat rentan terhadap perubahan lingkungan. Faktor-faktor yang mempengaruhi komunitas makroalga meliputi: faktor oseanografi, topografis, dan hayati (Ferawati et al., 2014).

\footnotetext{
Komunitas makroalga memiliki fungsi biologis, ekologis maupun ekonomis. Secara biologis makroalga berperan dalam meningkatkan produktivas primer, penyerap bahan polutan, penghasil bahan organik dan penghasil oksigen bagi biota akuatik lainnya. Secara ekologis makroalga berfungsi sebagai tempat memijah, tempat perlindungan serta tempat mencari makan bagi organisme sekitarnya. Secara ekonomi makroalga
}

dapat dimanfaatkan sebagai bahan industri kosmetik maupun farmasi (Dwimayasanti dan Kurnianto, 2018). Makroalga banyak ditemukan di pantai di Bali, khususnya di Pantai Geger dan Pantai Mengening.

Pantai Geger dan Pantai Mengening merupakan pantai yang terletak di Kabupaten Badung, Bali. Kedua pantai tersebut memiliki karakteristik yang berbeda serta anthopogenic aktivitas yang terdapat pada kedua pantai tersebut pun berbeda. Sehingga perbedaan tersebut mengakibatkan perbedaan organisme yang hidup di dalamnya. Kedua pantai tersebut terlihat memiliki keanekaragaman hayati yang melimpah, namun belum diketahui jumlah dan jenis makroalga yang terdapat pada kedua pantai tersebut. Tujuan dari penelitian ini yaitu untuk mengetahui perbedaan karakteristik habitat, jumlah jenis, biomassa basah serta perbedaan komunitas makroalga di Pantai Geger dan Pantai Mengening.

\section{METODE PENELITIAN}

\section{Waktu dan Lokasi Penelitian}

Penelitian ini dilaksanakan bulan Desember 2019 sampai Januari 2020. Jangka waktu tersebut mencakup studi literatur, survei lokasi, pengambilan data di lapangan, identifikasi sampel dan analisis data. Sampel diambil di Pantai Geger dan Pantai Mengening, Kabupaten Badung, Bali, sedangkan identifikasi sampel dan analisis data dilaksanakan di Laboratorium Perikanan Fakultas Kelautan dan Perikanan Universitas Udayana. Peta 
lokasi penelitian disajikan pada Gambar 1

dan Gambar 2.

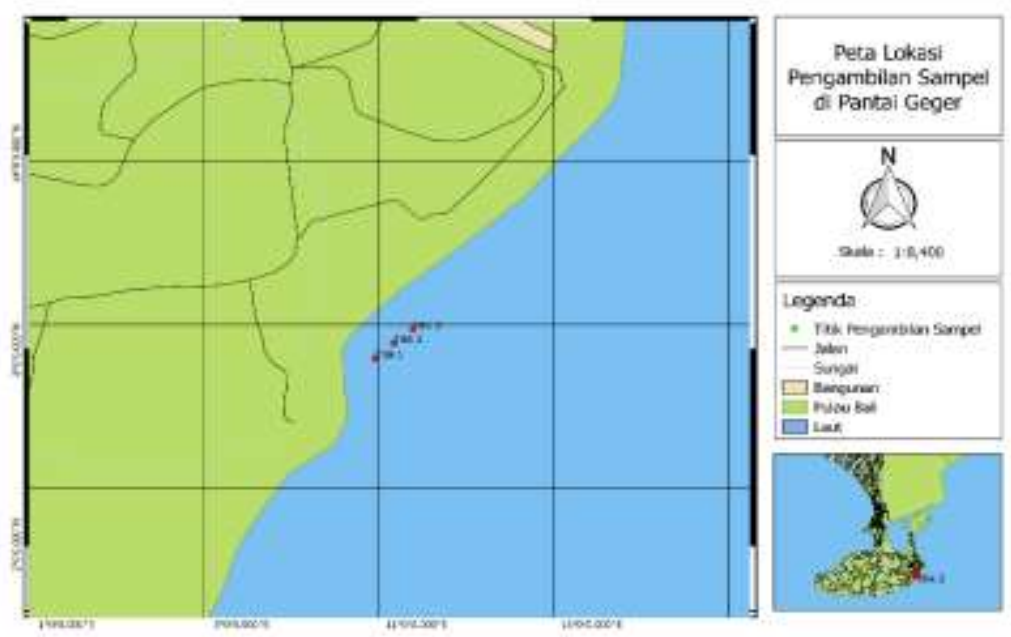

Gambar 1. Peta Pantai Geger

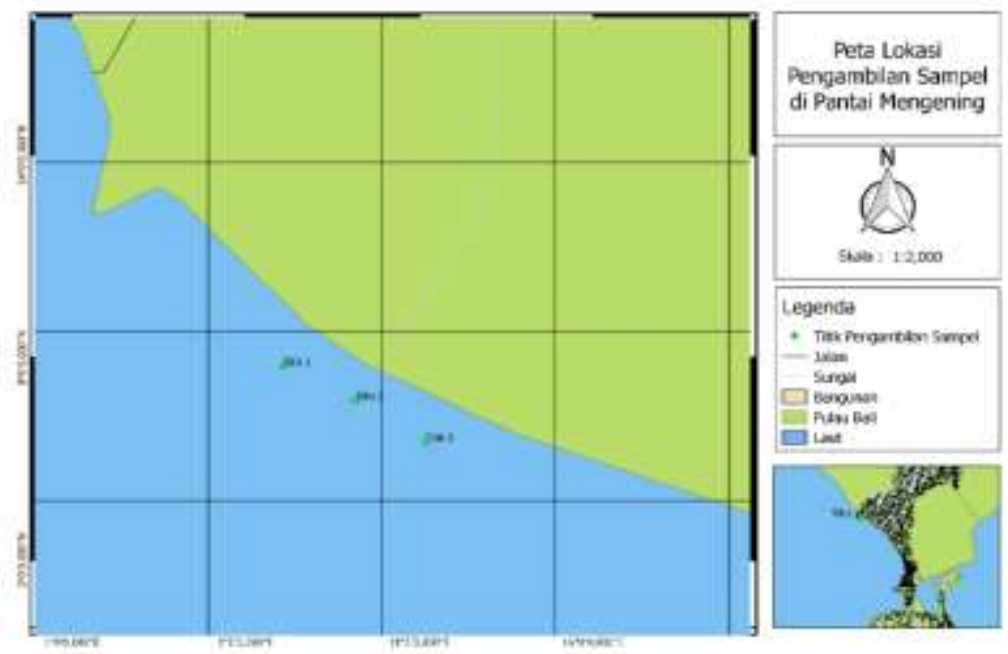

Gambar 2. Peta Pantai Mengening

Alat yang digunakan dalam penelitian ini meliputi : GPS, Transek Kuadran, Rollmeter, Refaktometer, pH meter, Thermometer, Turbiditymeter, Kamera, Plastik Sampel, Timbangan Digital, dan Coolbox. Bahan yang digunakan dalam penelitian ini adalah Makroalga, Tisu dan Aquadest.

\section{Metode Pengembilan Data}

Penelitian ini dilakukan dengan metode survei yaitu pengambilan data dengan menggunakan metode transek kuadran. Metode ini digunakan untuk menggambarkan kondisi dari suatu populasi yang mempunyai ukuran relatif beragam atau mempunyai ukuran maksimum tertentu. Pengambilan sampel dilakukan dengan meletakan transek di setiap titik pada masing-masing stasiun.

Kegiatan penelitian ini dilakukan di 2 stasiun, dimana Stasiun 1 berlokasi di di Pantai Geger sedangkan stasiun 2 berlokasi di Pantai Mengening. Pemilihan kedua stasiun didasari oleh adanya perbedaan karakteristik pada masing-masing pantai. 
Pantai Geger memiliki karakteristik pantai yang berpasir putih dengan ombak yang cukup tenang, sedangkan Pantai Mengening memiliki karakteristik pantai batuan karang serta ombak yang cukup besar. Pada setiap stasiun dibagi menjadi 3 titik lokasi dengan jarak antar titiknya yaitu $50 \mathrm{~m}$, dimana titik lokasi ditentukan berdasarkan keberadaan makroalga.

Pengambilan sampel makroalga dilakukan dengan menggunakan transek kuadran berukuran $1 \times 1$ meter yang dilakukan pada saat surut terendah. Pada saat pengambilan sampel, transek kuadran diletakkan di setiap titik secara acak pada masing-masing stasiun. Pengambilan sampel pada setiap titik dilakukan sebanyak lima kali untuk mewakili komunitas makroalga pada setiap titik pengamatan. Sampel makroalga yang terdapat pada setiap transek kuadran diambil dan dimasukkan ke dalam plastik yang telah diisi label, kemudian sampel tersebut di bawa ke laboratorium untuk dipisahkan jenisnya dan diidentifikasi berdasarkan genus maupun spesies.

Data parameter kualitas air diambil untuk menggambarkan kondisi lingkungan pada lokasi penelitian sebagai penunjang untuk kehidupan dan pertumbuhan makroalga. Data diambil sebelum dilakukan pengamatan pada sampel makroalga pada masing-masing titik dalam stasiun pengamatan. Pengambilan sampel air diambil menggunakan botol kemudian diukur secara in situ untuk parameter suhu, kekeruhan, $\mathrm{pH}$ dan salinitas. Sedangkan pengukuran parameter nitrat, fosfat dan oksigen terlarut dilakukan secara ex situ dilakukan di Laboratorium Perikanan, Fakultas Kelautan dan Perikanan, Universitas Udayana.
Sampel makroalga yang diambil pada setiap transek kemudian dipisahkan berdasarkan genusnya. Makroalga dibersihkan dengan menghilangkan kotoran yang penempel pada thallus kemudian ditimbang dengan menggunakan timbangan digital. Nilai biomassa makroalga dapat diketahui dengan menggunakan rumus dari Mishra (2018) dan Handayani (2017), yakni sebagai berikut:

$$
\mathrm{B}=\frac{\mathrm{TW}}{\mathrm{A}}
$$

Dimana B adalah biomassa $\left(\mathrm{g} / \mathrm{m}^{2}\right)$; TW adalah Biomassa genus i dalam kuadrat (g); dan A adalah luas total kuadrat $\left(\mathrm{m}^{2}\right)$.

\section{Analisis Data}

\section{Indeks Keanekaragaman}

Indeks keanekaragaman dihitung dengan menggunakan rumus Shannon Wiener (Krebs, 2021).

$$
\mathrm{H}^{\prime}=-\sum(\mathrm{ni} / \mathrm{N}) \operatorname{In}(\mathrm{ni} / \mathrm{N})
$$

Dimana $\mathrm{H}^{\prime} \quad$ adalah indeks keanekaragaman; ni adalah jumlah koloni setiap species; dan $\mathrm{n}$ adalah jumlah koloni seluruh species

Kriteria nilai indeks keanekaragaman Shannon- Wiener (H') :

$\mathrm{H}^{\prime} \leq 1 \quad$ : Keanekaragaman rendah, $1<\mathrm{H}^{\prime}<3$ : Keanekaragaman sedang $\mathrm{H}^{\prime} \geq 3 \quad$ : Keanekaragaman tinggi

\section{Indeks Dominansi}

Indeks Dominansi dihitung dengan menggunakan rumus Simpson (Fachrul, 2007)

$$
\mathrm{C}=\sum\left(\frac{n i}{N}\right)^{2}
$$

Dimana $\mathrm{C}$ adalah indeks dominansi; ni adalah jumlah individu ke-i; dan $\mathrm{N}$ adalah jumlah total individu 
Kriteria indeks dominansi dibagi dalam $0,00<\mathrm{C} \leq 0,50:$ Kategori rendah $0,50<\mathrm{C} \leq 0,75:$ Kategori sedang $0,75<\mathrm{C} \leq 1,00$ : Kategori tinggi

\section{Indeks Kemerataan}

Untuk mengetahui kemerataan yang digunakan adalah Indeks Eveness Pielou (E) (Fachrul, 2007).

$$
\mathrm{E}=\frac{H^{\prime}}{\ln S}
$$

Dimana E adalah i ndeks Eveness Pielou; H' adalah indeks keanekaragaman; dan $\mathrm{S}$ adalah jumlah jenis

Indeks kemerataan yang diperoleh kemudian dimasukkan dalam kriteria sebagai berikut:

$$
\begin{aligned}
& 0,00<\mathrm{C} \leq 0,50: \text { Komunitas tertekan } \\
& 0,50<\mathrm{C} \leq 0,75: \text { Komunitas labil } \\
& 0,75<\mathrm{C} \leq 1,00: \text { Komunitas stabil }
\end{aligned}
$$

\section{Penutupan Jenis Makroalga}

Estimasi persen penutupan makroalga digunakan estimasi yang dikembangkan oleh Atobe (1970). Dengan transek 1x1 meter dan kisi sebesar 20x20 cm. Kategori untuk setiap kisi-kisi degunakan skala 1/4, presentase penutupan jenis makroalga dapat dilihat pada Tabel 2. tiga kategori, antara lain:

$1 / 2,3 / 4$ dan 1 unit. Selanjutnya persen tutupan dihitung dengan menggunakan persamaan sebagai berikut :

$$
\mathrm{C}=\frac{\sum \mathrm{Ci}}{\mathrm{A}} \times 100 \%
$$

Dimana $\mathrm{C}$ adalah persentase tutupan; $\sum \mathrm{Ci}$ adalah jumlah unit tutupan setiap kisi-kisi setiap jenis makroalga; dan A adalah jumlah total kisi-kisi yang digunakan.

\section{HASIL DAN PEMBAHASAN \\ Hasil \\ Karakteristik Habitat Makroalga}

Karakteristik habitat makroalga di Pantai Geger dan Pantai Mengening meliputi jenis substrat dan kualitas air pada masing-masing pantai. Jenis substrat yang terdapat di Pantai Geger adalah substrat berpasir dan jenis substrat yang terdapat di Pantai Mengening merupakan substrat yang terdiri dari batuan karang. Hasil pengukuran kualitas perairan di Pantai Geger dan Pantai Mengening disajikan pada Tabel 1.

Berdasarkan hasil perhitungan diperoleh 8 jenis makroalga di Pantai Geger.

Tabel 1. Hasil Pengukuran Parameter Kualitas Air di Pantai Geger dan Pantai Mengening

\begin{tabular}{lccccccc}
\hline \multirow{1}{*}{ Parameter } & Satuan & \multicolumn{3}{c}{ Pantai Geger } & \multicolumn{3}{c}{ Pantai Mengening } \\
\cline { 3 - 7 } & & \multicolumn{3}{c}{ Rata-Rata } & Rata-Rata \\
\cline { 2 - 7 } & & Titik 1 & Titik 2 & Titik 3 & Titik 1 & Titik 2 & Titik 3 \\
\hline $\mathrm{pH}$ & - & 7,98 & 7,97 & 7,97 & 8,15 & 8,14 & 8,14 \\
Suhu & $0 \mathrm{C}$ & 30 & 30 & 30 & 29 & 29 & 29 \\
Kekeruhan & $\mathrm{NTU}$ & 1,06 & 1,24 & 0,47 & 1,18 & 0,98 & 0,59 \\
Salinitas & $0 / 00$ & 30 & 31 & 31 & 31 & 30 & 30 \\
Oksigen Terlarut & $0 / 000$ & 6 & 6.4 & 4 & 4 & 6.8 & 4.8 \\
Nitrat & $\mathrm{mg} / \mathrm{L}$ & 2,06 & 2,10 & 1,83 & 1,45 & 2,33 & 2,61 \\
Fosfat & $\mathrm{mg} / \mathrm{L}$ & 0,21 & 0,20 & 0,34 & 0,53 & 0,28 & 0,34 \\
\hline
\end{tabular}




\section{Presentase Penutupan Jenis Makroalga}

Tabel 2. Presentase Penutupan Jenis Makroalga di Pantai Geger

\begin{tabular}{lc}
\hline \multicolumn{1}{c}{ Spesies } & Presentase (\%) \\
\hline Ulva lactuca & $1,44-1,88 \%$ \\
Halimeda opuntia & $0,48-0,76 \%$ \\
Turbinaria ornate & $0,96-1,20 \%$ \\
Sargassum & $1,24-1,48 \%$ \\
echinocarpum & \\
Gracilaria edulis & $2,44-3,00 \%$ \\
Gracilaria hayi & $0,84-1,16 \%$ \\
Galaxaura & $0,88-1,12 \%$ \\
oblongata & \\
Palmaria palmata & $0,48-0,76 \%$ \\
\hline
\end{tabular}

Berdasarkan hasil perhitungan penutupan jenis makroalga di Pantai Mengening terdapat 10 jenis makroalga. Masing-masing presentase penutupan jenis makroalga disajikan pada Tabel 3.

Tabel 3. Presentase Penutupan Jenis Makroalga di Pantai Mengening.

\begin{tabular}{|c|c|}
\hline Spesies & Presentase (\%) \\
\hline Ulva lactuca & $4,20-7,84 \%$ \\
\hline $\begin{array}{l}\text { Valonia } \\
\text { aegagropila }\end{array}$ & $0,72-2,64 \%$ \\
\hline $\begin{array}{l}\text { Caulerpa } \\
\text { lentillifera }\end{array}$ & $0,96-1,28 \%$ \\
\hline $\begin{array}{l}\text { Halimeda } \\
\text { macroloba }\end{array}$ & $0,36-0,72 \%$ \\
\hline $\begin{array}{l}\text { Valoniopsis } \\
\text { pachynema }\end{array}$ & $0,20-0,52 \%$ \\
\hline Padina australis & $2,24-3,56 \%$ \\
\hline Sargassum binderi & $1,28-1,64 \%$ \\
\hline $\begin{array}{l}\text { Sargassum } \\
\text { polycystum }\end{array}$ & $0,68-1,48 \%$ \\
\hline $\begin{array}{l}\text { Halurus } \\
\text { equisetifolia }\end{array}$ & $0,60-1,16 \%$ \\
\hline $\begin{array}{l}\text { Galaxaura } \\
\text { oblongata }\end{array}$ & $0,44-1,40 \%$ \\
\hline
\end{tabular}

\section{Biomassa Makroalga}

Berdasarkan hasil perhitungan biomassa makrolaga di Pantai Geger dilihat pada Tabel 4.

Tabel 4. Biomassa Makroalga di Pantai Geger

\begin{tabular}{lc}
\hline \multicolumn{1}{c}{ Spesies } & Biomassa $\left(\mathrm{g} / \mathrm{m}^{2}\right)$ \\
\hline Ulva lactuca & $14,11-18,54 \mathrm{~g} / \mathrm{m}^{2}$ \\
Halimeda opuntia & $19,07-22,01 \mathrm{~g} / \mathrm{m}^{2}$ \\
Turbinaria ornate & $21,73-33,17 \mathrm{~g} / \mathrm{m}^{2}$ \\
Sargassum & $26,33-38,24 \mathrm{~g} / \mathrm{m}^{2}$ \\
echinocarpum & \\
Gracilaria edulis & $7,77-13,29 \mathrm{~g} / \mathrm{m}^{2}$ \\
Gracilaria hayi & $72,08-73,18 \mathrm{~g} / \mathrm{m}^{2}$ \\
Galaxaura & $65,55-71,23 \mathrm{~g} / \mathrm{m}^{2}$ \\
oblongata & \\
Palmaria palmata & $52,36-61,91 \mathrm{~g} / \mathrm{m}^{2}$ \\
\hline
\end{tabular}

Berdasarkan hasil perhitungan nilai biomassa makroalga di Pantai Mengening disajikan pada Tabel 5.

Tabel 5. Biomassa Makroalga di Pantai Geger

\begin{tabular}{lc}
\hline \multicolumn{1}{c}{ Spesies } & Biomassa $\left(\mathrm{g} / \mathrm{m}^{2}\right)$ \\
\hline $\begin{array}{l}\text { Ulva lactuca } \\
\text { Valonia } \\
\text { aegagropila }\end{array}$ & $42,31-44,59 \mathrm{~g} / \mathrm{m}^{2}$ \\
$\begin{array}{l}\text { Caulerpa } \\
\text { lentillifera }\end{array}$ & $181,31-190,40$ \\
Halimeda & $\mathrm{g} / \mathrm{m}^{2}$ \\
macroloba & $18,22-24,61 \mathrm{~g} / \mathrm{m}^{2}$ \\
Valoniopsis & $15,66-27,98 \mathrm{~g} / \mathrm{m}^{2}$ \\
pachynema & $23,45-33,85 \mathrm{~g} / \mathrm{m}^{2}$ \\
$\begin{array}{l}\text { Padina australis } \\
\text { Sargassum binderi }\end{array}$ & $3,40-6,77 \mathrm{~g} / \mathrm{m}^{2}$ \\
$\begin{array}{l}\text { Sargassum } \\
\text { polycystum }\end{array}$ & $26,03-27,12 \mathrm{~g} / \mathrm{m}^{2}$ \\
Halurus \\
equisetifolia \\
$\begin{array}{l}\text { Galaxaura } \\
\text { oblongata }\end{array}$ & $17,93-21,04 \mathrm{~g} / \mathrm{m}^{2}$ \\
\hline
\end{tabular}




\section{Indeks Keanekaragaman}

Nilai indeks keanekaragaman di perairan Pantai Geger dan Pantai Mengening disajikan pada Gambar 3.

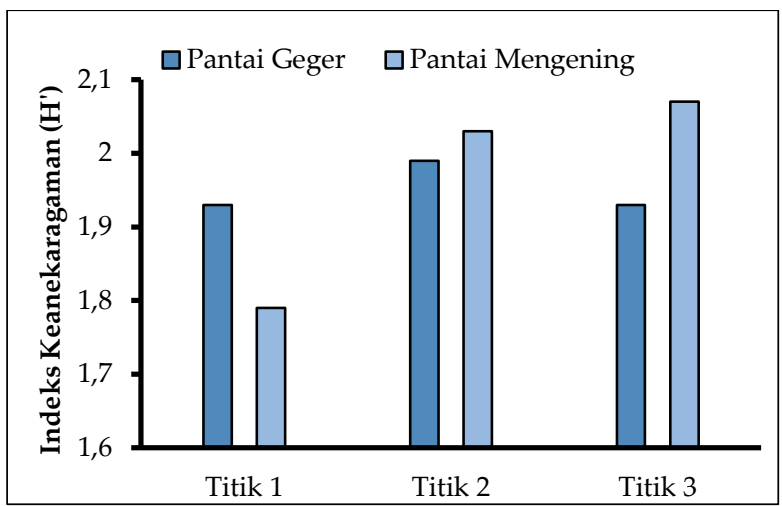

Gambar 3. Indeks Keanekaragaman Makroalga

Indeks keanekaragaman makroalga di Pantai Geger di titik 1 sebesar 1,93, di titik 2 sebesar 1,99 dan di titik 3 sebesar 1,93. Sedangkan indeks keanekaragaman makroalga di Pantai Mengening di titik 1 sebesar 1,79, di titik 2 sebesar 2,03 dan di titik 3 sebesar 2,07.

\section{Indeks Dominansi}

Indeks dominansi makroalga di perairan Pantai Geger dan Pantai Mengening disajikan pada Gambar 4

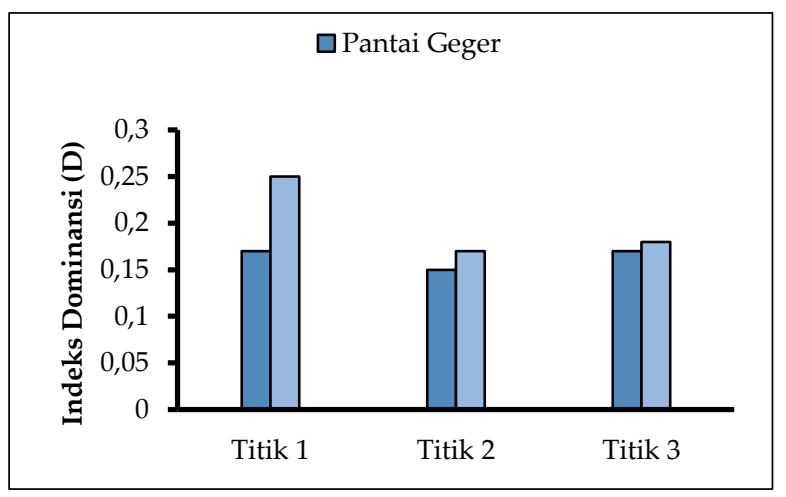

Gambar 4. Indeks Dominansi Maroalga

Indeks dominansi makroalga di Pantai Geger di titik 1 sebesar 0,17 , di titik 2 sebesar 0,15 dan di titik 3 sebesar 0,17. Sedangkan indeks dominansi di Pantai Mengening di titik 1 sebesar 0,25 di titik 2 sebesar 0,17 dan di titik 3 sebesar 0,18.

\section{Indeks Kemerataan}

Nilai indeks kemerataan makroalga di perairan Pantai Geger dan Pantai mengening disajikan pada Gambar 5.

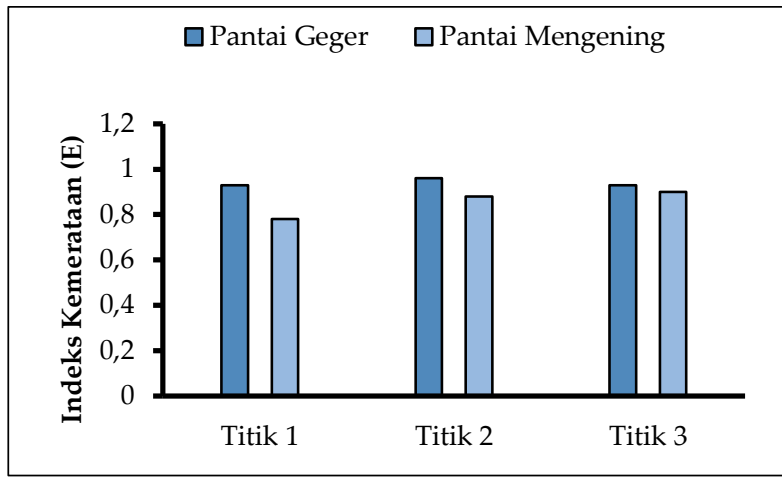

Gambar 5. Indeks Kemerataan Makroalga

Indeks kemerataan makroalga di Pantai Geger di titik 1 sebesar 0,93, di titik 2 sebesar 0,96 dan di titik 3 sebesar 0,93. Sedangkan indeks indeks kemerataan di Pantai Mengening di titik 1 sebesar 0,78, di titik 2 sebesar 0,88 dan di titik 3 sebesar 0,90 .

\section{Pembahasan \\ Karakteristik Habitat Makroalga}

Keberadaan makroalga di Pantai Geger dan Pantai Mengening dipengaruhi oleh jenis substrat. Jenis substrat yang terdapat di Pantai Geger adalah jenis substrat berpasir yang tergolong substrat yang tidak stabil sedangkan jenis substrat yang terdapat di Pantai Mengening merupakan jenis substrat yang terdiri dari batuan karang yang stabil. Pada substrat pasir jenis makroalga lebih sedikit dibandingkan substrat karang maupun pecahan karang karena pasir merupakan jenis substrat yang mudah terbawa oleh gelombang (Ferawati dkk, 2014).

Berdasarkan Tabel 1 hasil pengukuran kualitas air yang meliputi pengukuran $\mathrm{pH}$ yang dilakukan di lokasi penelitian menunjukan bahwa nilai rata-rata $\mathrm{pH}$ di 
Pantai Geger sebesar 7,97-7,98 sedangkan di Pantai Mengening sebesar 8,14-8,15. Menurut Anggadiredja et al., (2006) kondisi $\mathrm{pH}$ yang optimum untuk pertumbuhan makroalga berkisar antara 6,8-8,2. Rata-rata suhu di perairan Pantai Geger dan Pantai Mengening sebesar 29$30^{\circ} \mathrm{C}$,. Menurut Toni (2006), suhu normal untuk pertumbuhan makroalga berkisar antara $25-35^{\circ} \mathrm{C}$. Beberapa jenis makroalga memiliki suhu optimum yang lebih tinggi maupun lebih rendah dari kisaran tersebut.

Nilai rata-rata kekeruhan dari hasil pengukuran yang dilakukan di Pantai Geger sebesar 0,47-1,24 NTU di Pantai Mengening sebesar 0,59-1,18 NTU. Armita (2011) menyatakan, kekeruhan yang standar untuk pertumbuhan makroalga sebesar $20 \mathrm{mg} / \mathrm{L}$. Salinitas perairan di Pantai Geger dan Pantai Mengening sebesar 30-31\% $\%$. Pertumbuhan makroalga membutuhkan salinitas yang relatif tinggi antara 28-32 \% dan akan berpengaruh pada jumlah kepadataan yang lebih tinggi (Kerswell et al., 2006).

Berdasarkan hasil rata-rata pengukuran nilai oksigen terlarut (DO) di perairan Pantai Geger sebesar 4-6,4 mg/L sedangkan di Pantai Mengening sebesar 46,8 mg/L. Admadja (1996) menyatakan bahwa nilai oksigen terlarut yang baik bagi pertumbuhan makroalga $>6 \mathrm{mg} / \mathrm{L}$. Rata- rata nilai kandungan nitrat di dalam perairan Pantai Geger sebesar 1,83-2,10 $\mathrm{mg} / \mathrm{L}$ sedangkan di Pantai Mengening sebesar 1,45-2.61 mg/L. Kandungan nitrat yang baik untuk pertumbuhan makroalga berkisar antara 0,9-3,5 mg/L (Putinella 2001). Hasil rata-rata perhitungan nilai fosfat yang terkandung di perairan Pantai Geger sebesar 0,20-0,34 mg/L di Pantai Mengening sebesar 0,28-0,53 mg/L. Batas terendah konsentrasi fosfat untuk pertumbuhan makroalga berkisar antara 0,18-0,90 $\mathrm{mg} / \mathrm{L}$ dan batas tertinggi berkisar antara 8,90-17,8 mg/L (Patadjal, 2007).

\section{Presentase Penutupan Jenis}

Presentase penutupan jenis makroalga di Pantai Geger nilai presentase tertinggi ditemukan pada jenis Gracilaria edulis sebesar 2,44-3,00\% . resentase penutupan jenis makroalga tertinggi di Pantai Mengening terdapat pada jenis Ulva lactuca sebesar 4,20-7,84\% . Nilai presentase penutupan jenis makroalga di Pantai Geger dan Pantai Mengening tergolong rendah.

Rendahnya presentase penutupan jenis makroalga diduga disebabkan oleh aktivitas manusia. Pada daerah ini banyak terdapat berbagai aktivitas manusia seperti kegiatan pariwisata serta kegiatan mengambil beberapa jenis biota. Perbedaan nilai presentase penutupan makroalga pada masing-masing pantai diduga disebabkan oleh perbedaan substrat yang terdapat di Pantai Geger dan Pantai Mengening. Kadi (2007) menyatakan bahwa kombinasi substrat dasar akan membuat tutupan makroalga yang berbeda.

\section{Biomassa Makroalga}

Biomassa makroalga di setiap titik pada masing-masing memiliki nilai yang berbeda, hal tersebut dapat dipengaruhi oleh tipe substrat pada masing-masing pantai. Kondisi substrat yang didominasi oleh pecahan karang mendukung pertumbuhan dan perkembangan makroalga sedangkan substrat yang berlumpur akan menghambat penetrasi cahaya matahari jika teraduk oleh air (Priosambodo dan Ferial, 2006). Kadi (2007) menyatakan kesuburan dan biomassa rumput laut di suatu perairan dipengaruhi oleh kondisi lingkungan seperti keadaan substrat, kondisi perairan dan musim.

\section{Indeks Keanekaragaman}

Indeks keanekaragaman ( $\left.\mathrm{H}^{\prime}\right)$ makroalga yang terdapat di Pantai Geger dan Pantai Mengening Kabupaten Badung memiliki nilai yang berbeda pada masingmasing titik. Indeks keanekaragaman tertinggi di Pantai Geger berada pada titik 2 , terjadinya perbedaan nilai indeks 
keanekaragaman makroalga pada masingmasing titik di Pantai Geger diduga di titik 1 dan titik 2 terdapat hamparan padang lamun, namun padang lamun yang terdapat di titik 1 lebih tinggi dibandingkan dengan di titik 2 sehingga nilai indeks keanekaragaman dititik 2 lebih tinggi dibandingkan titik 1. Menurut Davis (2001) keberadaan makroalga dapat menjadi kompetitor bagi lamun dalam ekosistem yang sama, sehingga kompetisi antara makroalga dan lamun dalam memanfaatkan ruang dan nutrient seringkali mempengaruhi keberadaan lamun dan makroalga di ekosistem tersebut. Sedangkan dititik 3 tidak terdapat padang lamun, melainkan di titik 3 merupakan tempat untuk bersandarnya perahu.

Indeks keanekaragaman jenis tertinggi di Pantai Mengening ditemukan pada titik 3 dan terendah pada titik 1, perbedaan nilai indeks keanekaragaman antar titik di Pantai Mengening diduga dititik 3 dan titik 2 memiliki substrat yang terdapat batuan karang lebih banyak sehingga substrat di titik 2 dan 3 lebih stabil dibandingkan di titik 1. Menurut Pallalo (2011), kestabilan, kekerasan dan tekstur permukaan substrat memiliki arti penting dalam mendukung pertumbuhan makroalga.

Perbedaan nilai indeks keanekaragaman makroalga yang terdapat di Pantai Geger dan Pantai Mengening diduga dipengaruhi oleh jenis substrat pada masing-masing pantai. Jenis substrat yang terdapat di Pantai Geger adalah jenis substrat berpasir yang tergolong substrat yang tidak stabil sedangkan jenis substrat yang terdapat di Pantai Mengening merupakan jenis substrat yang terdiri dari batuan karang yang stabil sehingga dapat menyebabkan nilai indeks keanekaragaman di Pantai Mengening lebih tinggi dibandingkan di Pantai Geger. Atmadja (1999), menyatakan tempat-tempat yang memiliki subsrat stabil yang terdiri dari karang maupun pecahan karang memiliki keanekaragaman jenis yang lebih tinggi dibandingkan dengan substrat yang kurang stabil yang terdiri pasir maupun lumpur. Pada substrat pasir jenis makroalga lebih sedikit dibandingkan substrat karang maupun pecahan karang karena pasir merupakan jenis substrat yang mudah terbawa oleh gelombang (Ferawati dkk, 2014).

Dari perhitungan nilai indeks keanekaragaman makroalga yang terdapat di Pantai Geger dan Pantai Mengening termasuk kategori sedang. Kondisi tersebut dapat diartikan makroalga yang terdapat di Pantai Geger dan Pantai Mengening masih dalam keadaan baik.

\section{Indeks Dominansi}

Nilai indeks dominansi makroalga yang terdapat disetiap titik di Pantai Geger dan Pantai Mengening memiliki nilai yang tidak jauh berbeda. Nilai indeks dominansi di Pantai Mengening lebih tinggi dibandingkan dengan di Pantai Geger dengan kategori indeks dominansi rendah yang berarti tidak adanya spesies yang mendominansi. Hal ini berarti meratanya penyebaran jumlah individu pada setiap spesies di masing-masing titik pada setiap pantai. Odum (1993), menyatakan bahwa apabila nilai indeks dominansi mendekati 1 maka ada satu spesies yang mendominansi sedangkan apabila nilai indeks dominansi mendekati nol maka tidak ada spesies yang mendominansi.

\section{Indeks Kemerataan}

Indeks kemerataan jenis makroalga di Pantai Geger dan Pantai Mengening tidak jauh berbeda. Perbedaan nilai indeks kemerataan juga tidak jauh berbeda pada setiap titik di masing-masing pantai diduga persebaran makroalga pada setiap titik pada masing-masing pantai merata. Berdasarkan nilai indeks kemerataan, kondisi makroalga yang terdapat di Pantai Geger dan Pantai Mengening termasuk ke dalam kategori kondisi stabil. Hal ini dapat diartikan makroalga yang tersebar di Pantai Geger dan Pantai Mengening merata. Menurut Hasrun, dkk (2013) jika indeks kemerataan mendekati 1, dapat menunjukkan bahwa 
penyebaran individu dalam satu spesies tidak ada perbedaan yang signifikan.

\section{Kesimpulan}

Pantai Geger dan Pantai Mengening memiliki karakteristik habitat yang berbeda. Pantai Geger memiliki karakteristik habitat dengan substrat berpasir yang tergolong kurang stabil sehingga mudah terbawa oleh gelombang sehingga holdfast dan thallus makroalga kurang kuat melekat pada substart tersebut sedangkang Pantai Mengening memiliki karakteristik habitat dengan substrat yang terdiri dari batuan karang yang tergolong stabil yang baik untuk pertumbuhan makroalga. Kondisi kualitas air $(\mathrm{pH}$, suhu, salinitas, kekeruhan,oksigen terlarut, nitrat dan fospat) pada masing-masing pantai masih sesuai untuk pertumbuhan makroalga.

Biomassa makroalga di Pantai Geger yaitu: Ulva lactuca 14,11-18,54 g/ $\mathrm{m}^{2}$, Halimeda opuntia 19,07-22,01 g/ $\mathrm{m}^{2}$, Turbinaria ornate 21,73-33,17 g/m², Sargassum echinocarpum 26,33-38,24 $\mathrm{g} / \mathrm{m}^{2}$, Gracilaria edulis 7,77-13,29 g/ $\mathrm{m}^{2}$, Gracilaria hayi $72,08-73,18 \mathrm{~g} / \mathrm{m}^{2}$, Galaxaura oblongata $65,55-71,23 \mathrm{~g} / \mathrm{m}^{2} \mathrm{dan}$ Palmaria palmata $52,36-61,91 \mathrm{~g} / \mathrm{m}^{2}$ dan biomassa makroalga di Pantai Mengening yaitu: Ulva lactuca 42,31-44,59 $\mathrm{g} / \mathrm{m}^{2}$, Valonia aegagropila 181,31-190,40 g/m ${ }^{2}$, Caulerpa lentillifera 18,22-24,61 $\mathrm{g} / \mathrm{m}^{2}$, Halimeda macroloba 15,66-27,98 g/m $\mathrm{m}^{2}$, Valoniopsis pachynema $23,45-33,85 \mathrm{~g} / \mathrm{m}^{2}$, Padina australis $3,40-6,77 \mathrm{~g} / \mathrm{m}^{2}$, Sargassum binderi 26,03-27,12 g/m², Sargassum polycystum 17,93-21,04 g/m ${ }^{2}$, Halurus equisetifolia $36,33-42,75 \mathrm{~g} / \mathrm{m}^{2} \mathrm{dan}$ Galaxaura oblongata 55,26-61,96 g/2 .

Nilai indeks keanekaragaman di Pantai Geger dan Pantai Mengening termasuk kedalam kategori sedang, nilai indeks dominansi di Pantai Geger dan Pantai Mengening termasuk kedalam kategori rendah dan nilai indeks kemerataan di Pantai Geger dan Pantai
Mengening termasuk ke dalam kategori stabil.

\section{Saran}

Pantai Geger dan Pantai Mengening merupakan pantai yang tingkat keanekaragaman yang sedang dimana kondisi tersebut masih dalam keadaan baik. Untuk mempertahankan kondisi tersebut diperlukan upaya untuk menjaga kondisi habitat makroalga di kedua pantai tersebut agar kelestarian makroalga tersebut tetap lestari. Disarankan untuk peneliti selanjutnya agar menganalisa biota yang berasosiasi pada makroalga serta memperluas area penelitian sehingga dapat menganalisa pola distribusi makroalga.

\section{Daftar Pustaka}

Anggadiredja, J. T, Zatnika A, Purwoto H, Istini S. 2006. Rumput Laut. Jakarta: Penebar Swadaya.

Armita D. 2011. Analisis perbandingan kualitas air di daerah budidaya rumput laut dengan daerah tidak ada budidaya rumput laut, di Dusun Malelaya, Desa Punaga, Kecamatan Mangarabombang, Kabupaten Takalar. [Skripsi]. Makasar: Universitas Hasanudin.

Atmadja, W.S. 1996. Pengenalan Jenis Algae Coklat (Phayophyta) Dalam Pengenalan Jenis-Jenis Rumput Laut Indonesia. Jakarta: Puslitbang Oseanologi LIPI.

Atmadja, W.S. 1999. Karakteristik Algae Makro (rumput laut) yang Tumbuh di Perairan Samudra Hindia. Prosiding. Seminar Pra Kipnas VII Forum Komunikasi Ikatan Fikologi Indonesia. Serpong 8 september 1999: 21-29.

Davis, C.B., J.W. Fourqurean. 2001. Competition Between the Halimeda 
incassata, and the Seagrass Thalassia testudinum. Aqua. Botani. 71:217232.

Dwimayasanti, R dan Kunianto, D. 2018. Kominitas Makroalga di Perairan Tayando-Tam, Maluku Tenggara. Oseanologi dan Limnogi di Indonesia 20183 (1): 39-48

Fachrul MF. 2007. Metode Sampling Bioekologi . Jakarta: Bumi Aksara.

Ferawati, E., Widyartini, D. S., \& Insan, I. 2014. Studi Komunitas Rumput Laut Pada Berbagai Substrat Di Perairan Pantai Permisan Kabupaten Cilacap. Scripta Biologica, 1(1), 57-62.

Handayani, T. 2017. Potensi Makroalga di Paparan Terumbu Karang Perairan Teluk Lampung. Oseanologi dan Limnogi di Indonesia 2017 2(1): 5567

Hasrun, L. O., Kasim, M., \& Salwiyah. 2013. Studi Biodiversitas Diatom Bentik pada Areal Mangrove di Perairan Kecamatan Kolono Kabupaten Konowe Selatan. Jurnal Mina Laut Indonesia, 02(06), 35-47.

Kadi, A. 2007. Kondisi habitat dan komunitas makro algae di perairan Pulau Simeulue Aceh Barat paska tsunami. Oseanologi dan Limnologi di Indonesia-LIPI 33:427-439.

Kerswell, A. P., 2006. Global Biodiversity Patterns of Bentic Marine Algae. Krebs CJ. 2001. Ecology. The Experiment Analisys of Distribution and Abundance 5th First Edition. New York: Harper and Row, Publishers.
Mishra, A. (2018) Sargassum, Gracilaria and Ulva Exhibit Positive Antimicrobial Activity against Human Pathogens. Open Access Library Journal, 5, 1-11. doi: 10.4236/oalib.1104258.

Odum, E.P. 1993. Dasar-Dasar Ekologi. Penerjemahan: Samingan, T dan B. Srigandono. Gajahmada University Press. Yogyakarta.

Pallalo, A. 2013. Distribusi Makroalga Pada Ekosistem Lamun dan Terumbu Karang di Pulau Bonebatang, Kecamatan Ujung Tanah, Kelurahan Barrang Lompo, Makasar [Skripsi]. Makasar: Universitas Hasanudin.

Patadjal, R. S. 2007. Pertumbuhan Produksi dan Kualitas Rumput Laut Kappaphycus alvarenzii pada Berbagai Habitat Budidaya yang Berbeda. Program Pasca Sarjana. Universitas Hasanudin. Makassar.

Priosambodo, D. dan E.W. Ferial. 2006. Analisis vegetasi makroalga di rataan terumbu karang Pulau Katindoang Kecamatan Sinjai Utara Kabupaten Sinjai. Jurnal Bioma 1(2):31-45.

Putinella, J.D., 2001. Evaluasi Lingkungan Budidaya Rumput Laut Di Teluk Bagula

Maluku.http://www.coremap.or.id/do wnload/0121.pdf (akses tanggal : 31 Maret 2020).

Toni, 2006. Inventarisasi Jenis Makroalga di Pulau Sertung dan Pulau Serabi Selatan Sunda Lampung. Laporan Kerja Praktik. Jakarta: Departemen Biologi Universitas Indonesia. 